\title{
TESTING FOR AN OCEANIC ROLE IN CREATING LOW LATITUDINAL TEMPERATURE GRADIENTS DURING CRETACEOUS WARMTH
}

MACLEOD*, Kenneth G., Department of Paleobiology, National Museum of Natural History, Smithsonian Institution, MRC: NHB 121, Washington, D.C. 20560, U.S.A.; HUBER, Brian T., Department of Paleobiology, National Museum of Natural History, Smithsonian Institution, MRC: NHB 121, Washington, D.C. 20560, U.S.A.

Numerous studies demonstrate that the middle through Late Cretaceous was an interval of global warmth with reduced latitudinal thermal gradients and ice-free polar regions. Low latitudinal thermal gradients are characteristic of greenhouse intervals; however, model simulations for the Cretaceous and other warm intervals predict steeper temperature gradients than are estimated from empirical data. These differences indicate shortcomings in our understanding of the climate system and/or our interpretation of geologic data, and resolving them is an important goal of paleoclimatic research. Model simulations have shown that increases in oceanic heat transport, high latitude cloud cover, or high latitude vegetation may be significant factors in creating warm polar regions. To test the role of oceanic processes in determining latitudinal temperature gradients, we are generating stable isotopic data from various planktic and benthic taxa and cataloging the global distribution of inoceramid bivalves in DSDP/ODP Micropaleontological Reference Center (MRC) samples. The mechanism commonly invoked to achieve increased oceanic heat transport is poleward movement of warm, saline water masses. Therefore, we are particularly interested in whether the benthic record shows evidence of these water masses, especially at the times the planktic data indicate greenhouse conditions.

Our survey of the occurrence of inoceramid remains in MRC samples is not complete, but the preliminary data are equivocal. At bathyal paleodepths in the South Atlantic, intervals containing abundant inoceramid remains are correlated with decreased differences in $\delta^{18} \mathrm{O}$ between planktic and benthic foraminifera (consistent with saline bottom waters). On the other hand, neither unusually high inoceramid abundances nor low vertical $\delta^{18} \mathrm{O}$ gradients occur at the time planktic $\delta^{18} \mathrm{O}$ data from DSDP Site 511 (Falkland Plateau) indicate peak temperatures and extremely low latitudinal thermal gradients $\left(0-4^{\circ} \mathrm{C}\right.$ across more than $50^{\circ}$ latitude). An essentially flat latitudinal gradient is difficult to reconcile with intuition. Regardless, while we have found evidence for temporal variations in bottom water conditions, these variations are not consistently associated with evidence for high latitude warmth.

Detailed data from Maastrichtian samples, though, do provide strong evidence that warm, saline water masses were a significant climatic factor during the Late Cretaceous. Temperatures declined throughout the Campanian and Maastrichtian, but faunal changes (including extinction among inoceramids) are concentrated in the mid-Maastrichtian. Stable isotopic data from several mid- to high latitude DSDP/ODP cores suggest that bottom waters became cooler and less saline coincident with the inoceramid extinction. That this shift correlates with widespread ecological change suggests the change in deep water circulation could have acted as a climatic switch that temporally focused change. If elevated oceanic heat transport is needed to maintain "greenhouse" temperature distributions, latitudinal temperature gradients should have increased coincident with the inferred change in ocean circulation. We are now testing this hypothesis. 